\title{
The assesment of the quality of postoperative pain management in patients with maxillofacial injury
}

\section{Ocena bólu u pacjentów po zabiegach z zakresu chirurgii szczękowo-twarzowej}

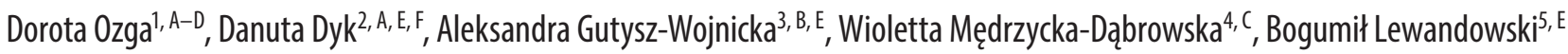 \\ 1 Department of Didactics in Intensive Medical Care and Emergency Medicine, Faculty of Medicine, University of Rzeszów, Rzeszów, Poland \\ 2 Department of Anesthesiological and Intensive Care Nursing, Poznan University of Medical Sciences, Poznań, Poland \\ 3 Department of Nursing, Faculty of Medical Sciences, University of Warmia and Mazury, Olsztyn, Poland \\ ${ }^{4}$ Department of General of Nursing, Medical University of Gdansk, Gdańsk, Poland \\ ${ }^{5}$ Department of Emergency Medicine, Faclty of Medicine, University of Rzeszów, Rzeszów, Poland \\ A - research concept and design; $\mathrm{B}$ - collection and/or assembly of data; $\mathrm{C}$ - data analysis and interpretation; \\ $D$ - writing the article; $E$ - critical revision of the article; $F$ - final approval of article
}

Address for correspondence

Dorota Ozga

E-mail: gdozga@poczta.fm

\section{Funding sources}

none declared

Conflict of interest

none declared

\section{Acknowledgements}

The authors would like to thank the team: dr hab. n. med. Bogumił Lewandowski and mgr Małgorzata Migut from Clinical Ward of the Maxillofacial Surgery at the Hospital № 1 in Rzeszów (Poland) for their help and support during the research.

Received on January 2, 2017

Revised on January 12, 2017

Accepted on March 26, 2017

DOI

$10.17219 / \mathrm{dmp} / 69758$

Copyright

() 2017 by Wroclaw Medical University

and Polish Dental Society

This is an article distributed under the terms of the

Creative Commons Attribution Non-Commercial License

(http://creativecommons.org/licenses/by-nc-nd/4.0/)

\section{Abstract}

Background. Postoperative pain is acute pain. Its prevalence is associated not only with the course of the disease but also with surgical damage to the tissue or the organs as well as the surgical wound.

Objectives. The aim of the paper is to evaluate the quality of perisurgical care in the aspect of postoperative pain in patients with a maxillofacial injury.

Material and methods. The study involved 198 patients. The research included all the patients diagnosed with a maxillofacial injury who were admitted to the Clinical Ward of Maxillofacial Surgery.

Results. The average score in the clinical quality indicators in postoperative pain management was 47.89 and did not reach the minimal level of 63 . A current intensification of pain amounted to 2.14 on average \pm 1.54 . In the $24 \mathrm{~h}$ time period the most severe postoperative pain was $4.55 \pm 2.03$, whereas the mildest pain experienced came to $2.4 \pm 2.36$. Satisfaction with the pain alleviation method was high, $7.71 \pm 1.97$. It has been proven that there is a correlation between the general score of the clinical quality indicators in postoperative pain management and the pain level according to the VAS scale, which as evaluated during the first $24 \mathrm{~h}$ after the surgery proved a significant dependency $(p=0.0000)$. The surveyed patients, who gave higher notes to the quality of pain treatment experienced pain amounting up to 4 pts. (minor pain) on the VAS scale.

Conclusions. Generally, the quality of the nursing care considering the postoperative pain management received average notes. The level of experience in postoperative pain management is higher in younger patients, who are university graduates suffering from mild pain as well as the patients with upper face injury.

Key words: postoperative pain, perisurgical care, care quality

Słowa kluczowe: ból pooperacyjny, opieka okołooperacyjna, jakość opieki 
Postoperative pain treatment in Poland requires significant improvement. The Polish Society for Pain Research (PTBB) took certain steps to introduce a set of principles regulating postoperative pain management. In 2001 a team of experts at the PTBB along with the Polish Gynecological Society laid down regulations concerning acute pain treatment after gynecological procedures. In June 2008 PTBB published: Alleviating postoperative pain - 2008 recommendations. The regulations focused specifically on the safety of administering analgetics, the necessity to monitor postoperative pain and provide proper nursing education for the personnel. Postoperative pain is not dependent solely on the postoperative wound, but is conditioned by many factors such as the patient's psychological profile, former experience with pain, cultural and environmental elements (i.e. hospital conditions). In 2011 in Poland an updated version of the publication: "2011 recommendations - acute and postoperative pain management" came out, followed by the next one in 2014. Current regulations include the basic issues of postoperative pain treatment as formed in Evidence Based Medicine (EBM). ${ }^{1-4}$ The reason to evaluate the quality of postoperative pain treatment is to gather information concerning the nursing care provided to the patients and to work out whether the existing assumptions were accomplished as well as to define potential areas which need improvement. It is believed that every patient has the right to high quality medical care, and it is the hospital employees' duty to provide it. ${ }^{5,6}$ It is stated that in many cases postoperative pain treatment is inadequate. Some of those patients experience pain ranging from moderate to severe. Klopfenstein et al. claim that the reason for the low quality of postoperative pain treatment is insufficient education and training on the part of the workers as well as the patients, lack of communication between the workers and the patients, varying methods used to evaluate and treat pain, lack of systematic medical documentation, evaluating only the rest pain and lack of social awareness. ${ }^{7}$ Both nurses and doctors share a tendency to under appreciate patients' pain and to diminish it. $^{6-10}$ The studies published indicate that $80 \%$ of the patients at surgical wards experience pain, $45 \%$ of them describe it as unbearable. ${ }^{11}$ Setting a pain management program for each hospital unit has significant meaning in pain management. Such guidelines would consider the unit's specificity and character. ${ }^{11}$ It is important to define how nurses rank the quality of the postoperative pain treatment and whether the result is in line with the patients' evaluation. ${ }^{5,7,12}$ Unrelieved pain may be a serious health problem; however, according to the literature it may be averted. Very often the pain accompanying the patients' treatment is neglected due to the lack of effective pharmacological or non-pharmacological therapies. Unrelieved pain causes increasing reaction, which affects the immunological system and delays wound healing. ${ }^{11}$ Unrelieved pain is a risk factor causing the development of chronic pain syndrome. On the other hand, however, a proper postoperative an- algesia is associated with lower cardiopulmonary complications risk, fewer fatalities and lower treatment costs. ${ }^{11}$ Hospitals do their best to introduce the established guidelines and to improve their practice. Many people implemented projects to improve the quality of the system in order to change structures and practices concerning the patient's care. Unfortunately, relatively few such projects have been successful. As Dahl et al. claim, only a few publications indicate that the aforementioned efforts lead to better results in treating patients. ${ }^{11}$

The aim of the paper is to evaluate the quality of the postoperative pain treatment in patients with a maxillofacial injury treated surgically and to identify areas requiring improvement concerning care quality.

\section{Material and methods}

The study included 198 patients admitted to the Clinical Ward of Maxillofacial Surgery in the Regional Hospital in Rzeszów. The patients were qualified based on the inclusion criteria. The study group varied considering sex, age, place of residence, education and financial status. The choice of the patients for the study trial was purposeful. The inclusion criteria included: hospitalization due to injury; emergency or elective surgical procedure; no cognitive disorders; written consent to participate in the study, informing about the aim of the study and the time needed to complete the questionnaire; minimum 18 years old. The exclusion criteria were: life threatening situations and transferring the patient in an induced coma to the ICU for further treatment. The dependency between the evaluated treatment quality and pain intensity in the postoperative period, the type of injury, demographic and environmental factors were analyzed.

The research tools used were scales: Verbal Rating Scale (VRS), Visual Analogue Scale (VAS), Strategic and Clinical Quality Indicators in Postoperative Pain Management (KWJPZBP) as adapted in Poland.

The VAS scale allows the patient to define the intensity of pain as a variable subjective characteristic, which may take a continuous value and cannot be directly measured with other available tools. Patients define the intensity of pain using VAS scale by marking a point on a $10 \mathrm{~cm}$ $(100 \mathrm{~mm})$ line, where 0 is the absolute lack of pain and $10 \mathrm{~cm}$ is the most severe pain possible. The results are interpreted as following: 1-25 $\mathrm{mm}$ means mild pain, 26-50 mm - moderate pain, $51-75$ - severe pain and 76-100 mm - maximal pain. VRS scale evaluates scale in a descriptive way. The patient can describe pain by using a scale from 0 to $5 .{ }^{13-16}$ The Polish version of Strategic and Clinical Quality Indicators in Postoperative Pain Management (KWJPZBP) was validated and culturally adapted by the Department of Neurological and Psychiatric Nursing at the Nursing Institute of the Poznan University of Medical Sciences. Authors of the Polish version consented to 
the use of this tool in the study. ${ }^{17}$ Strategic and Clinical Quality Indicators in Postoperative Pain Management consists of 14 statements organized in 4 subscales: communication (statements 1, 11 and 14), action (statements 2, 3, 6 and 7), trust (statements 5, 8, 12 and 13) and environment (statements 4, 9 and 10). In the communication and environment subscales patients can gain 4-20 points. In Action and Trust subscales the point range is 3-15. The tool also contains 1 question concerning the patient's general satisfaction with pain treatment as well as 3 complementary questions about the intensification of postoperative pain. The respondents could rank the statements on a 5-point Likert scale. One means definite disagreement, whereas 5 definite agreement. According to the authors, the theoretical range of the scale amounts to 14-70 points. In accordance with authors' assumptions, high quality care reaches 4.5 or more points obtained in reference to each statement separately. If the score is lower it is assumed that the level of care for a given issue diverges from the demanded quality and should be improved. Similarly, if the patient ranks a statement with 1 or 2 points he or she is put in a group of patients whose care quality should be refined. The minimal general score should amount to 63 points or higher. In reference to the communication and environment subscales, the score should reach 13.5 points, action and trust subscales -18.0 points. ${ }^{5,12}$ The intensity of the pain experienced has been evaluated on the basis of independent questions using an 11 -point scale, where 0 points meant lack of pain whereas 10 points meant very severe pain. Psychometric values (alfa Cronbach coefficient) for the Polish version of Strategic and Clinical Quality Indicators in Postoperative Pain Management appeared to be satisfying, with the exception of Communication and Environment subscales, where the values were lower (0.70). This fact could be a result of a small number of statements included in the subscales. They amounted to: entire scale -0.90 , communication subscale -0.64 , action subscale -0.69 , trust subscale -0.80 , environment subscale $-0.65 .^{18,19}$

The study was conducted after obtaining consent of the Bioethical Committee at the Poznan University of Medical Sciences (No 1239, Dec $18^{\text {th }}$ 2008). Participation in the study was voluntary. The patients were granted confidentiality and were ensured that, although it would be possible to identify the patient based on the registry number and the questionnaire number, the researchers would use the data obtained in the poll only for scientific purposes.

The study group consisted of 198 patients hospitalized from January $1^{\text {st }} 2009$ to December $31^{\text {st }} 2009$. All patients diagnosed with a maxillofacial injury and admitted to the Clinical Ward of the Maxillofacial Surgery in Rzeszów took part in the study. All the patients underwent a surgical procedure. The questionnaires were given to 198 patients. Hundred percent of the forms were returned, with incomplete ones. Hundred and ninety-five questionnaires were qualified for further analysis, which constituted $98.0 \%$ of the initial group. Population under study consisted of 195 people, including 173 men (88.7\%) and 22 women (11.3\%); 33.8\% were patients aged $21-30$. Almost $1 / 3$ (34.8) of the respondents were $31-50$ years old, $15.9 \%$ up to 20 years old, $8.7 \%$ - 51-60 years old and $6.6 \% 61$ years old or older.

The biggest group among the respondent - 96 patients (49.0\%) were people living in the countryside, then 70 patients $(36.0 \%)$ in a county town. The smallest group consisted of people living in a voyevodship city - 29 (15.0\%). When asked about the source of income the respondents listed: professional work - 85 patients (45.9\%), pension/ retirement - 12 people each (6.5\%), no regular income - 16 people $(16.2 \%)$, other sources - 24 people (24.9\%). Ten patients did not answer the question. Among the 195 respondents, 77 people (39.5\%) presented a secondary education, 50 (25.6\%) vocational education, 49 (25.1\%) primary and 19 people (9.7\%) higher education. For the sake of the study the injuries were divided into 3 types. Types of injury were defined as type I injury - upper face fracture/ forehead sinus/the bridge of nose/ethmoid bone, type II injuries - mid face fracture including maxilla, the base of the nose as well as malar bones and malar arches and type III lower face fracture, mandible. ${ }^{20}$ The injury in the facial part of the cranium that was most common in the study group was a mid-face fracture, including the maxilla, the base of nose along with malar bones and malar arches - 93 patients (44.28\%). The next most common type of injury was a lower face fracture, that is the mandible -79 patients $(37.61 \%)$. A part of the respondents (7.14\%) suffered from an upper face injury. 4 patients $(1.90 \%)$ experienced both upper and mid face injury. Two patients had a mid and lower face injury. During the study there was only 1 case of an upper, mid and lower face injury.

\section{Organization and the process of data collection}

The place for conducting the research was chosen based on the unit's specificity and innovativeness of the treatment methods applied at the ward. The Clinical Ward for Maxillofacial Surgery is the only ward in the Subcarpathian region. Patients admitted to the ward are transferred there directly from the emergency room and from other hospitals when in need of hospitalization. The ward has a third reference level. After obtaining the consent of the hospital's administration and the ward chief doctor, preparatory steps were taken to complete the research documentation. The project began on January $1^{\text {st }} 2009$ and took 12 months to complete.

\section{Statistical analysis}

The analysis was performed using the statistical package STATISTICA v. 10, Polish version along with SPSS program. The statistical analysis included basic measurement 
adjusted to the variables that is mean, standard deviation, minimal and maximal values. The variables measured on a quotient scale - age was described using an arithmetic mean and standard deviation (SD). The variables measured nominally: sex, education, source of income were presented as numerical data, quantity (n) and percentage showing the share of a given variable in the study group. The variables measured on an ordinal scale, such as: pain level were presented with descriptive statistics including median, minimal and maximal values. The following nonparametric test was incorporated: Mann Whitney test, Spearman rank correlation coefficient, Kruskal-Wallis test, the Fischer test (for small groups). The following rules were set: $\mathrm{p}<0.5$ - statistically significant dependency (marked by *); p < 0.01 - highly significant dependency (marked by *); p < 0.001 - dependency of extremely high significance (marked by $* * \%)$.

\section{Results}

\section{Assessment of the quality of postoperative pain management with the use of Polish version of the strategic and clinical quality indicators in postoperative pain management}

The assessment of the care quality in reference to postoperative pain and the exacerbation of pain were presented as follows: the average result for the entire scale in the group of patients was 47.89 points (range 14-70) and did not reach the minimal value of 63 . In regards to the subscales, the minimal score (as recommended by the authors of the original version) was not reached as well.5,12,18,21,22 In the communication subscale the lowest score applied to the statement concerning information about possible methods of pain relief was 2.87 points (range $1-5$ ). The majority of the respondents (54.1\%) ranked those aspects negatively giving them 1 or 2 points. Less than a half of the patients in the study (36.8\%) declared, however, that they had come across a quantity evaluation of the pain intensification done by the medical personnel after the surgery. In the action subscale, the score concerning the quantity of pain evaluation done by the personnel amounted to 2.67 points. Low score, 2.80 applied to communication concerning postoperative pain alleviation plan. In the trust subscale, statement no. 13 got the lowest score, 3.43. None of the 4 statements in the trust subscale obtained the minimum of 4.5 points, which means that the level of care terms of trusting the nursing personnel is insufficient. In the environment subscale the aspect with the lowest score was connected to the hospital room - 3.59 points. Table 1 presents the scoring for the general result and each subscale separately (Table 1).

\section{The assessment of the postoperative pain on a strategic and clinical indicators of quality of the postoperative pain management scale}

Pain intensity in patients at the moment of examination was 2.14 on average $\mathrm{SD}=1.54$. Pain experienced during $24 \mathrm{~h}$ described as the most severe amounted to $4.55 \mathrm{SD}=2.03$, whereas the mildest pain came to 2.34 $\mathrm{SD}=2.36$. Satisfaction with the applied method of pain relief was relatively high, $7.71 \mathrm{SD}=1.97$. The majority of the patients ( $\mathrm{n}=136 ; 75.1 \%$ ) stated the pain they experienced after the procedure was in accord with what they expected or milder. The rest of the patients $(n=45 ; 24.9 \%)$ claimed the pain they felt was more severe than expected (Table 2).

The dependency of the general strategic and clinical indicators of quality of postoperative pain management result and the pain level on VRS scale evaluated in the first $24 \mathrm{~h}$ proved to be significant $(\mathrm{z}=11.66 ; \mathrm{p}<0,001)$. The respondents who ranked the treatment quality as high on the strategic and clinical indicators of quality of the postoperative pain management scale rated their pain up to 4 point (a mild pain) on VAS scale.

\section{The influence of the chosen factors on the assessment of the quality of postoperative pain management}

The value of test statistics in analyzing the dependence between the age of the respondents and the general score on the strategic and clinical indicators of quality of postoperative pain management scale was $\mathrm{z}=8.72$; $\mathrm{p}<0.001$. The highest score was given by people aged $20-30$. There were no statistically significant differences in the general score between male and female groups and each of the 4 subscales: communication, action, trust, and environment. The impact of patients' education on the general score was analyzed. The value of the test statistic was $\mathrm{h}=12.37 ; \mathrm{p}<0.001$. It marks a statistically significant dependency between patients' education and a general score on the strategic and clinical indicators of quality of postoperative pain management scale. The highest scores regarding the quality of care were given by people with secondary education. Both for the general score as well as for particular subscales in reference to the place of residence no statistically significant differences were found. When it comes to the dependency between the source of income and the general strategic and clinical indicators of quality of postoperative pain management score no statistically significant dependencies were found. The analysis concerning dependencies between the subscales results and the type of injury showed statistically significant correlations between the action subscale and type I injury - upper face fracture/forehead sinus/bridge of nose/eth- 
Table 1. Patients' assessment of the quality of postoperative pain management with the use of Polish version of the strategic and clinical quality indicators in postoperative pain management

\begin{tabular}{|c|c|c|c|}
\hline Subscales & Mean & $\pm \mathrm{SD}$ & $\mathrm{N}(\%)$ score 1 or 2 \\
\hline 1 & 2 & 3 & 4 \\
\hline COMMUNICATION (subscale range: $3-15$ ) [13.5 pts*] & 10.37 & 2.8 & - \\
\hline 1. I was informed about the pain relief methods before the surgery & 2.87 & 1.2 & $70(36.8 \%)$ \\
\hline $\begin{array}{l}\text { 11. When nurses start to come on duty they know everything about the pain I am experiencing } \\
\text { and the treatment I have received }\end{array}$ & 3.68 & 1.4 & $17(8.9 \%)$ \\
\hline 14. The nurses and doctors cooperate in the pain management process & 3.87 & 1.2 & $16(8.4 \%)$ \\
\hline ACTION (subscale range: 4-20) [18 pts*] & 12.28 & 3.25 & - \\
\hline 2. I talked to the nurses about the methods I wish the pain to be treated with after the surgery & 2.80 & 1.36 & $46(24.2 \%)$ \\
\hline 3. I received help in finding a comfortable position in bed, which would allow me to avert pain or minimize it & 3.07 & 1.37 & $32(16.8 \%)$ \\
\hline $\begin{array}{l}\text { 6. The personnel asked me about the pain when they noticed I was uneasy, was breathing heavily } \\
\text { or kept changing my position }\end{array}$ & 3.74 & 1.24 & $19(10.0 \%)$ \\
\hline $\begin{array}{l}\text { 7. The personnel asked me to describe the pain level on a scale from } 1 \text { to } 10 \text { at least once in the morning, } \\
\text { at noon and in the evening }\end{array}$ & 2.67 & 1.43 & $93(48.9 \%)$ \\
\hline TRUST (subscale range: 4-20) [18 pts*] & 14.57 & 3.26 & - \\
\hline 5. Even if I did not ask for pain medication I always received it & 3.81 & 1.22 & $14(7.4 \%)$ \\
\hline 8. The nurses helped me to relieve pain until I did not feel better & 3.65 & 1.42 & $52(27.4 \%)$ \\
\hline 12. The nurses are knowledgeable about how to relieve my pain & 3.66 & 1.35 & $6(3.2 \%)$ \\
\hline 13. The nurses believed me when I told them that I am not in pain & 3.43 & 1.38 & $19(10.0 \%)$ \\
\hline ENVIRONMENT (subscale range: 3-15) [13.5 pts*] & 10.67 & 3.26 & - \\
\hline 4. I was granted peace and quiet to sleep well & 3.76 & 1.23 & $2(1.1 \%)$ \\
\hline 9. The room was nice and comfortable & 3.14 & 1.54 & $39(20.5 \%)$ \\
\hline 10. The number of nurses during a shift has been sufficient enough to respond quickly to my request for pain relief & 3.59 & 1.48 & $12(58.9 \%)$ \\
\hline General score (subscale range 14-70) [63 pts*] & 47.44 & - & - \\
\hline
\end{tabular}

$\left[{ }^{*}\right]$ desired minimal score.

moid bone. The Spearman rank correlation coefficient was 0.6; $\mathrm{p}<0.001$. In regards to communication, trust and environment subscales and type II injuries, such as midface fracture including maxilla, the base of nose as well as malar bones and malar arches and type III injuries, the lower face fracture, mandible there were no statistically significant correlations found.

\section{Discussion}

Strategic and clinical indicators of quality of postoperative pain management scale is a study tool used to measure the quality of the postoperative pain treatment. The average result of the postoperative pain management in the original study was 47.89 and did not reach the desired minimal score of 63. Taking into consideration particular areas, it was stated that in the communication subscale the aspect of informing the patient about possible methods of pain alleviation obtained the lowest score. The percentage of patients who evaluated this aspect negatively was 54.1. In the study Jaracz et al. ${ }^{17}$ this amounted to $40 \%$, whereas in the study Bączyk et al. ${ }^{23}$ and Juszczyk ${ }^{18}-35 \%$, and in Herrera-Espineira et al. ${ }^{24}$ Thirty-two percent of the respondents were not satisfied with the information received in the hospital. The above data indicates that there is a need to provide the sick with more detailed information concerning pain alleviation methods after surgery. In the study by Sierpińska and Dzirba, which evaluated the level of satisfaction with nursing care by means of an original questionnaire, the majority of respondents (99.3\%) gave a positive score to 'explaining and informing the patients. 25

Table 2. Postoperative pain and care satisfaction according to the patients on the strategic and clinical indicators of quality of postoperative pain management scale

\begin{tabular}{|c|c|c|c|c|}
\hline Assessment aspects & Scale range & Mean & SD & Min-Max \\
\hline Current pain intensity & $0-10$ & 2.14 & 1.54 & $0-10$ \\
\hline Pain exacerbation during the first $24 \mathrm{~h}$ after the procedure & $0-10$ & 4.55 & 2.03 & $0-9$ \\
\hline The mildest pain during the first $24 \mathrm{~h}$ after the procedure & $0-10$ & 2.34 & 2.36 & $0-6$ \\
\hline Level of satisfaction with the pain alleviation methods applied & $0-10$ & 7.71 & 1.97 & $2-10$ \\
\hline
\end{tabular}


Only $0.7 \%$ ranked the information given by nurses as negative and very negative. In the action subscale the lowest scores were given to the statements concerning the possibilities of making joint decisions about the methods alleviating postoperative pain and measuring pain intensity. In the trust subscale the score was close to the desired one, which means that the care quality in this aspect is quite high. In the environment subscale the place of stay - the hospital room was ranked with the lowest score. Twenty point five percent expressed their dissatisfaction in this matter. The level of satisfaction with the pain alleviation method applied was $7.71 \mathrm{SD}=1.97$. The highest score was 10 , and the lowest 2 . Similar values were presented by Jaracz et al. ${ }^{17}-8.64$ and Bączyk et al. ${ }^{23}-9.31$. The respondents assessed the treatment quality in the first $24 \mathrm{~h}$ after the surgery with higher scores in the pain range less than 4 (mild pain). It has been noted that there is a dependency between the patients' age and the general score in the strategic and clinical indicators of quality of postoperative pain management scale. The highest scores were given by patients aged 20-30, which is not confirmed in the studies by Jaracz et al. ${ }^{17}$, Bacczyk et al. ${ }^{23}$, and Juszczyk. ${ }^{18}$ No dependency was found between the sex, place of residence or the source of income and the general score as well as each of the 4 subscales. In the observations conducted by many authors no such dependency was found as well. When it comes to the education and its impact on the general score of the strategic and clinical indicators of quality of postoperative pain management scale, it has been shown that patients with secondary level education evaluated the postoperative pain treatment with the highest scores. The research by Żakowska et al. shows that higher education predisposes patients to higher scores. ${ }^{14}$ The statistical analysis showed that there is a correlation between the score of Action subscale and type I injury, upper face fracture. In the studies by Idvall et al. the general score concerning the assessment of the nursing care fluctuated from 2.8 to 4.7 points. ${ }^{26}$ The average results for the nurses varied from 3.3 to 54.8 points for the same questions. The difference occurred in all of the subscales. In 2 of them (communication and action) the quality of care was evaluated both by the patients as well as the nurses at lower scores than the level that was defined as clinically realistic, for instance: "The personnel asked me about the pain when taking deep breaths, getting out of bed or moving". The difference in 2 other subscales (trust and environment) indicated to higher results for the quality provided in reality in comparison to the level defined by the nurses as realistic. For example "I was given an opportunity to rest peacefully so that I can sleep at night". The average score for the question concerning the sufficient number of nurses was $4.1 \pm 0.9$.

Pain is the most common problem in adult patients before surgery. It is an even bigger problem than the fear of whether the surgery improves the clinical condition. There are a few significant aims in postoperative pain treatment for instance minimizing and eliminating discomfort. It is unethical not to take proper actions to relieve pain when patients are suffering. The nurses play a key part in monitoring pain and are able to evaluate the effectiveness of the treatment. The process of taking care of the patient requires systematic and scientifically based methods of conducting treatment. The intervention of nurses may include procedures other than pharmacological, observations, health education. ${ }^{26-28}$ In Sweden, a concept of specific care quality for the postoperative stage was formed. It assumes that effective pain alleviation does not only include tangible pain minimization but also focuses on improving patient's comfort and general satisfaction of the postoperative care. Reaching those targets depends on proper pharmacological therapy as well as factors associated with pharmacotherapy and pain monitoring and factors connected with information, nursing personnel work quality along with factors concerning providing optimal conditions for sleep and night rest. A study tool for evaluating the quality of the postoperative treatment and pain alleviation satisfaction was established on the basis of the aforementioned concept. ${ }^{27}$ The researchers agree as to the statement that the patient's subjective assessment is one of the most crucial indicators of the quality of health care. ${ }^{29}$

\section{Conclusions}

Generally, the quality of nursing care in regards to postoperative pain management received average notes. The level of experience in postoperative pain management is higher in younger patients, who are university graduates and suffer from mild pain as well as in patients with upper face injuries.

\section{Implications for practice}

The studies conducted in Poland indicate that there is a need to monitor the quality of postoperative pain treatment and to promote constant improvement, specifically in the areas such as: information about possible pain alleviation methods, analgesic treatment, possibilities of joint decision making when pain alleviation is considered as well as hospital conditions during the patient's treatment.

\section{References}

1. Mędrzycka-Dąbrowska W, Ogrodniczuk M, Dąbrowski S, Basiński A. The organization and functioning of postoperative pain management in the UK. Anestezjol Rat. 2012;6:475-483 (in Polish).

2. Mędrzycka-Dąbrowska W, Ogrodniczuk M, Dąbrowski S. The role of nurses in the treatment of postoperative pain - part I. Anestezjol Rat. 2012;6:332-338 (in Polish).

3. Misiołek H, Mayzner-Zawadzka E, Dobrogowski J, Wordliczek J. The 2011 guidelines for acute pain and post-operative pain management. Ból. 2011;12:9-33 (in Polish).

4. Misiołek H, Cettler M, Woroń J, Wordliczek J, Dobrogowski J, Mayzner-Zawadzka E. The 2014 guidelines for post- operative pain menagement. Anaesthesiol Intens Ther. 2014;46:221-244. 
5. Idvall E, Hamrin E, Unosson M. Development of instrument to measure strategic and clinical quality indicators In postoperative pain management. J Adv Nurs. 2002;37:532-540.

6. Crowe L, Chang A, Fraser Ja, Gaskill D, Nash R, Wallace K. Systematic review of the effectiveness of nursing interventions in reducing or relieving post-operative pain. Internat J Evid Bas Healthcare. 2008;6: 396-430.

7. Klopfenstein CE, Herrmann FR, Mamie C. Pain intensity and pain relif after surgery. Acta Anaesthesiol Scand. 2000;44:58-62.

8. Sloman R, Rosen G, Rom M, Shir Y. Nurses' assessment of pain in surgical patients. J Adv Nurs. 2005;52:125-132.

9. Walker JA. What is the effect of preoperative information on patient satisfaction? Br J Nurs. 2007;16:27-32

10. Buckley H. Nurses management of post- operative pain. Contempor Nurse. 2000;9:148-154.

11. Dahl JL, Gordon D, Ward S, Skemp M, Wochos S, Schurr M. Institutionalizing pain management: The post-operative pain management qua improvement project. J Pain. 2003;4:361-371.

12. Idvall E, Hamrin E, Sjöström B, Unosson M. Patient and nurse assessment of quality of care in postoperative pain management. Quality Safety Health Care. 2002;11:327-334.

13. Tymecka I, Flis E. Diagnozing pain in children (pilot study). Ann Uniwersit Mariea Curie-Skłodowska. 2000;64:323-329 (in Polish).

14. Wasilewski T. Subjective assessment of selected aspects of satisfaction with hospital stay in patients of surgical wards. Pieleg Chirurg Angiol. 2008;3:81-86 (in Polish).

15. Machata AM, Kabon B, Willschke $H$, et al. A new instrument for pain assessment in the immediate postoperative period. Anesth. 2009;64:394-398.

16. Hjermstad M-J, Fayers P, Haugen D, Garaceni A. Studies comparing numerical rating scales, verbal rating scales, and visual analogue scales for assessment of pain intensity in adults: A systematic literature review. J Pain Symptom Manag. 2011;41:1073-1093.

17. Jaracz K, Wdowczyk K, Górna K. Evaluation of the quality of care in terms of postoperative pain using the Polish version of the scale of clinical indicators of management quality of postoperative pain. Pielęg Pol. 2005;19:9-14 (in Polish).

18. Juszczyk K. Factors influencing patient satisfaction with nursing care in light of the research. Pieleg Chirurg Angiol. 2013;8,115-117 (in Polish).

19. Juszczyk K. The role of nurse In postoperative pain management. Pieleg Chirurg Angiol. 2009;4:131-134 (in Polish).

20. Wanyura H. Facial skull injuries. Kryst L. (ed.). Chirurgia Szczękowotwarzowa. PZWL. Warszawa 2007 (in Polish).

21. Gunningberg L, Idvall E. The quality of postoperative pain management from the perspectives of patients, nurses and patient records. J Nurs Manag. 2007:15:756-766

22. Idvall E, Hamrin E, Rooke L, Sjostrom B. A tentative model for developing strategic clinical nursing quality indicators: Postoperative pain management. Internat J Nurs Pract. 1999;5:216-226

23. Bączyk G, Ochmańska M, Stępień S. Subjective assessment of the quality of nursing care in terms of postoperative pain in patients treated surgically. Probl Pieleg. 2009;17:173-177 (in Polish).

24. Herrera-Espineira C, Del Mar Rodriguez Del Aguila M, Rodriguez Del Castillo M, Fernandez Valdivia A, Reyes Sanchez I. Relationship between anxiety level of patients and their satisfaction with different aspects of healthcare. Health Policy. 2009;89:37-45.

25. Sierpińska $L$, Dzirba $A$. The level of patient satisfaction with nursing care on surgical wards. Pieleg Chirurg Angiol. 2011;6:18-22 (in Polish).

26. Idvall E. Quality of care in postoperative pain management: What is realistic in clinical practice? J Nurs Manag. 2004;12:162-166.

27. Idvall E, Mamrin E. Quality indicators In postoperative pain management: A validation study. Scand J Caring Sci. 2001;15:331-338.

28. Soderhamm O, Idvalle. Nurses`influence on quality of care In postoperative pain management: A phenomenological study. Internat J Nurs Pract. 2003;9:26-32.

29. Gutysz-Wojnicka A, Dyk D, Cudak E, Ozga D. Measuring patient satisfaction with the Polish version of the Newcastle Satisfaction with Nursing Scale. Scand J Caring Sci. 2013;27:311-318. 